\title{
HCV-related liver and lymphoproliferative diseases: association with polymorphisms of IL28B and TLR2
}

Valli De $\mathbf{R e}^{1, *}$, Mariangela De Zorzi ${ }^{1, *}{ }^{1}$, Laura Caggiari ${ }^{1}$, Gianfranco Lauletta ${ }^{2}$, Maria Lina Tornesello3 ${ }^{3}$ Elisa Fognani ${ }^{4}$, Marta Miorin', Vito Racanelli', Luca Quartuccio7, Laura Gragnani ${ }^{4}$, Sabino Russi ${ }^{2}$, Fabio Pavone ${ }^{2}$, Michela Ghersetti ${ }^{8}$, Elena Garlatti Costa $^{8}$, Pietro Casarin ${ }^{8}$, Riccardo Bomben ${ }^{9}$, Cesare Mazzaro ${ }^{9}$, Giancarlo Basaglia ${ }^{10}$, Massimiliano Berretta ${ }^{11}$, Emanuela Vaccher ${ }^{11}$, Francesco Izzo ${ }^{12}$, Franco Maria Buonaguro3, Salvatore De Vita7, Anna Linda Zignego ${ }^{4}$, Paolo De Paoli ${ }^{13}$ and Riccardo Dolcetti ${ }^{14,15}$

${ }^{1}$ Bio-Proteomics Facility/ Cancer Bioimmunotherapy, Department of Translational Research, Centro di Riferimento Oncologico (CRO), National Cancer Institute, Aviano, Italy

${ }^{2}$ Liver Unit, Division of Internal Medicine and Clinical Oncology, Department of Biomedical Sciences and Human Oncology, University of Bari Medical School, Bari, Italy

${ }^{3}$ Molecular Biology and Viral Oncology Unit, Istituto Nazionale Tumori "Fondazione G. Pascale" - IRCCS, Napoli, Italy

${ }^{4}$ Interdepartmental Center for Systemic Manifestations of Hepatitis Virus MASVE, Department of Experimental and Clinical Medicine, University of Florence, Florence, Italy

${ }^{5}$ Cytogenetics and Molecular Biology Unit, Santa Maria degli Angeli Hospital Pordenone, Pordenone, Italy

${ }^{6}$ Immunology Section, Department of Biomedical Sciences and Human Oncology, University of Bari Medical School, Bari, Italy

${ }^{7}$ Clinic of Rheumatology, Department of Medical and Biological Sciences, University Hospital "Santa Maria della Misericordia", Udine, Italy

${ }^{8}$ Internal Medicine-Liver Unit, Santa Maria degli Angeli Hospital Pordenone, Pordenone, Italy

${ }^{9}$ Clinical and Experimental Onco-Hematology Unit, Centro di Riferimento Oncologico (CRO), National Cancer Institute, Aviano, Italy

${ }^{10}$ Microbiology-Immunology and Virology Unit, Centro di Riferimento Oncologico (CRO), National Cancer Institute, Aviano, Italy

${ }^{11}$ Medical Oncology, Centro di Riferimento Oncologico (CRO), National Cancer Institute, Aviano, Italy

12 Hepatobiliary Unit, Istituto Nazionale Tumori "Fondazione G. Pascale" - IRCCS, Napoli, Italy

${ }^{13}$ Scientific Directorate, Centro di Riferimento Oncologico (CRO), National Cancer Institute, Aviano, Italy

${ }^{14}$ Cancer Bio-Immunotherapy, Department of Translational Research, Centro di Riferimento Oncologico (CRO), National Cancer Institute, Aviano, Italy

15 University of Queensland Diamantina Institute, Translational Research Institute, Brisbane, Queensland, Australia

* These authors have equally contributed to this study as first authors

Correspondence to: Valli De Re, email: vdere@cro.it

Keywords: HCV, TLR2, IL28B, HCC, NHL, Immunology and Microbiology Section, Immune response, Immunity

Received: February 12, $2016 \quad$ Accepted: April 19, $2016 \quad$ Published: May 11, 2016

\section{ABSTRACT}

To explore the relationship between innate immunity and hepatitis C Virus (HCV) in determining the risk of cirrhosis (CIR), hepatocellular carcinoma (HCC), mixed cryoglobulinemia syndrome (MCS) and non-Hodgkin lymphoma (NHL), we investigated the impact of the toll-like receptor-2 (TLR2) and interleukin-28B (IL28B) genetic variants. TLR2 -174 del variant was associated with TLR2 expression and with specific downstream molecules that drive the expression of different interleukins; rs12979860 II28B was important in response to interferon-treatment and in spontaneous clearance of HCV. The risk for liver and lymphoproliferative diseases in HCV progression was clarified by stratifying 862 HCV-positive patients into groups based on liver (CIR, HCC) and lymphoproliferative HCV-related diseases (MCS, NHL) 
and compared with chronic HCV (CHC) infection. Analysis of TLR2-IL28B haplotypes showed an association of wild type haplotype with the lymphoproliferative diseases (OR 1.77, $p=0.029)$ and a slight increase in HCV viral load (HR 1.38, $p=0.054)$. Wild type haplotype (TLR2 ins/ins- IL28B C/C) was also found associated with older age in patients with an hepatic diseases (in CIR and in HCC $p=0.038$ and $p=0.020$, respectively) supporting an effect of innate immunity in the liver disease progression. TLR2 and IL28B polymorphisms in combination showed a role in the control of HCV viral load and different HCV disease progression.

\section{INTRODUCTION}

Chronic HCV-infection (CHC) may induce cirrhosis and hepatocellular carcinoma (HCC), but also B-cell dysregulations such as autoimmune type II mixed cryoglobulinemia syndrome (MCS) and B-cell non-Hodgkin lymphoma (NHL) [1-3]. The mechanisms whereby HCV establishes hepatic or lymphoproliferative diseases are still poorly understood.

Innate immune response relies on recognition of pathogen-associated molecular patterns (PAMP) through pattern recognition receptors (PRRs) that include the tolllike receptors (TLRs). TLR2, TLR3, TLR7 and TLR9 have a crucial role in host defense against $\mathrm{HCV}$ infection and HCV liver diseases [4-7]. Like other TLRs (TLR1, TLR4, TLR5, TLR6 and TLR10), TLR2 is predominantly expressed on the cell surface to sense extracellular PAMPs. In contrast, TLR3, TLR7, TLR8 and TLR9 are located in intracellular compartments and recognize viral nucleotides. TLR2 has been associated with hepatocarcinogenesis and is known to be triggered by the core-protein of the HCV nucleocapsid [8-12]. Intriguingly, specific TLR polymorphisms, mainly the TLR2 -196 to $-174 \mathrm{ins} / \mathrm{del}$, influence the extent of TLR2 expression and have been associated with more advanced liver diseases $[13,14]$. TLRs signal through specific downstream molecules that finally activate transcription factors driving the expression of different cytokines including interferons $[15,16]$.

Inappropriate production of interferons has been associated to various $\mathrm{HCV}$-related processes that may be the prelude to malignant complications $[17,18]$. Interferon-lamba (IFN $\lambda$ ) is a family of four genes: IFN $\lambda 1$ (IL29), IFN $\lambda 2$ (Il28A), IFN 33 (IL28B) and IFN $\lambda 4$ (a frameshift variant of IL28B) [19]. They target the IL28R $\alpha$ and IL10Rb receptors resulting in the activation of Janus kinase/signal transducers and activators of transcription (JAK/STAT) signaling with expression of interferonstimulated genes (ISGs) and induction of an antiviral state. However, unlike type I IFN receptor, which was expressed on virtually all cell types, IL28R $\alpha$ was only expressed on specific tissues such as epithelia [20]. A single nucleotide polymorphism (SNP) in the promoter region of the IL28B gene, the rs12979860, was originally associated with spontaneous and treatment-induced clearance of genotype $1 \mathrm{HCV}$ infection $[2,17,21-26]$.
We hypothesized that, if TLR2 and IL28B were functionally interconnected in $\mathrm{HCV}$ diseases-specific networks, both TLR2 and IL28B polymorphisms could have a critical role in the pathogenesis of HCV-related disorders.

To test this hypothesis, we investigated TLR2 -196 to $-174 \mathrm{ins} / \mathrm{del}$ and rs12979860 IL28B polymorphisms in $\mathrm{HCV}$-related liver and lymphoproliferative diseases in an Italian population.

\section{RESULTS}

\section{Patients characteristics and group distribution}

Patient characteristics and group distribution were shown in Table 1. Gender and HCV genotypes were found differentially distributed among HCV-related disease groups. Male gender was preferentially found associated with liver diseases (CIR and HCC; 67 to 71\%), while female gender was more frequent in patients with lymphoproliferative disorders (MCS and NHL; 63 and $61 \%$ ). HCV genotype 1 was the most frequent genotype found in our population (53 to $82 \%$ ). No association between HCV genotypes and HCV viral load was observed.

Genotype frequencies of TLR2 ins/del polymorphism in chronic $\mathrm{HCV}$ infection, $\mathrm{HCV}$ related liver and lymphoproliferative diseases

Figure 1 shows the genotype frequencies of TLR2 ins/del (-196 to -174) polymorphism in patients with HCV, HCV-related diseases and blood donors (BD). Distribution of BD TLR2 ins/del genotype frequencies in our case series was similar to that reported in the literature [13]. Carriers of wild-type TLR2 (ins/ins) genotype represented $71.6 \%$ of all HCV-positive patients, with a frequency of $70 \%$ to $77 \%$ in the different $\mathrm{HCV}$-related diseases, and $75 \%$ in BD (Figure 1). Data indicated a slight association between TLR2-del allelic variant with HCV infection, but the difference was not significant when polymorphism frequencies of all $\mathrm{HCV}$-positive patients were compared to those of BD (dominant TLR2 ins/ins vs TLR2 ins/del + TLR2 del/del, OR $=1.20$, Table 2). However, patients 
TLR2

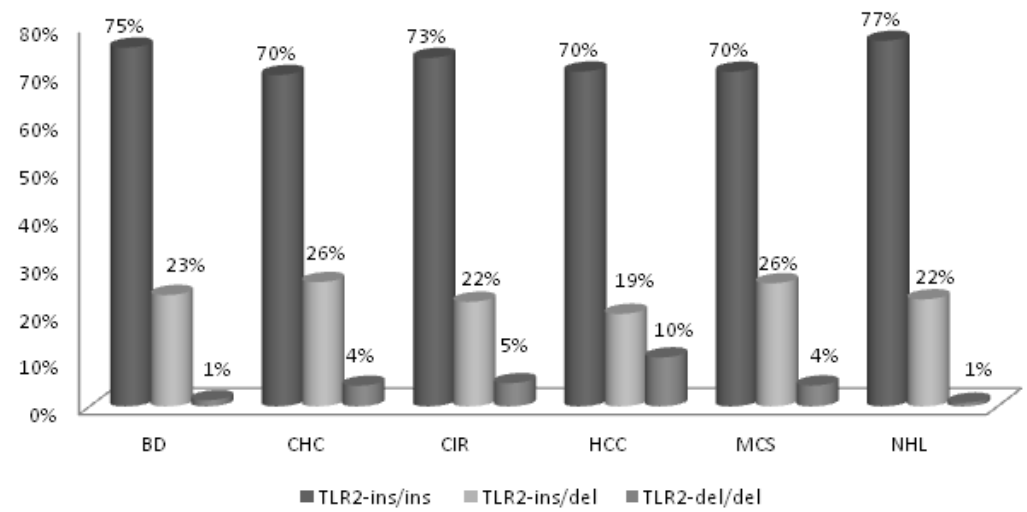

\begin{tabular}{|c|ccc|c}
\hline & $\begin{array}{c}\text { TLR2- } \\
\text { ins/ins } \\
\text { n. }\end{array}$ & $\begin{array}{c}\text { TLR2- } \\
\text { ins/del } \\
\text { n. }\end{array}$ & $\begin{array}{c}\text { TLR2- } \\
\text { del/del } \\
\text { n. }\end{array}$ & $\begin{array}{c}\text { Tot } \\
\text { n. }\end{array}$ \\
\hline BD & 58 & 18 & 1 & 77 \\
CHC & 160 & 60 & 10 & 230 \\
CIR & 90 & 27 & 6 & 123 \\
HCC & 123 & 34 & 18 & 175 \\
MCS & 144 & 53 & 9 & 205 \\
NHL & 99 & 29 & 1 & 129 \\
\hline
\end{tabular}

\section{IL28B}

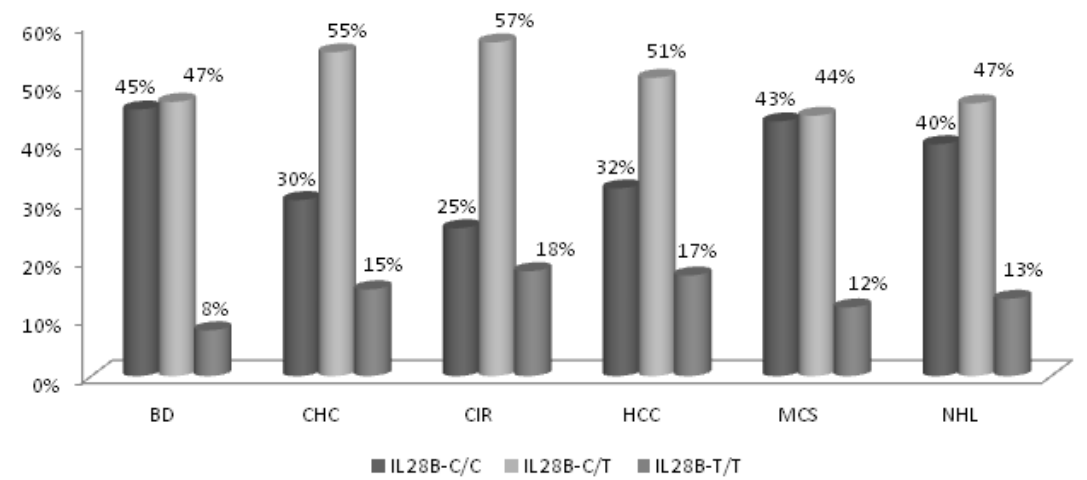

\begin{tabular}{|c|c|c|c|c|}
\hline & $\begin{array}{c}\text { IL } 28 B- \\
\text { C/C } \\
n .\end{array}$ & $\begin{array}{c}\text { IL } 28 \mathrm{~B}- \\
\mathrm{C} / \mathrm{T} \\
\mathrm{n} .\end{array}$ & $\begin{array}{c}\text { IL } 28 \mathrm{~B}- \\
\mathrm{T} / \mathrm{T} \\
\mathrm{n} .\end{array}$ & $\begin{array}{c}\text { Tot } \\
\text { n. }\end{array}$ \\
\hline$B D$ & 35 & 36 & 6 & 77 \\
\hline $\mathrm{CHC}$ & 69 & 127 & 34 & 230 \\
\hline CIR & 31 & 70 & 22 & 123 \\
\hline HCC & 56 & 89 & 30 & 175 \\
\hline MCS & 89 & 91 & 24 & 205 \\
\hline NHL & 51 & 60 & 17 & 129 \\
\hline
\end{tabular}

Figure 1: Distribution of TLR2 and IL28B genotypes among HCV-positive population groups. TLR2 and IL28B genotypes frequencies and relative number of cases in patients with chronic HCV infection (CHC), with HCV-related cirrhosis (CIR), with HCVrelated hepatocellular carcinoma (HCC), with HCV-related mixed cryoglobulinemic syndrome (MCS), with HCV-related non Hodgkin lymphoma (NHL) and in blood donors (BD).
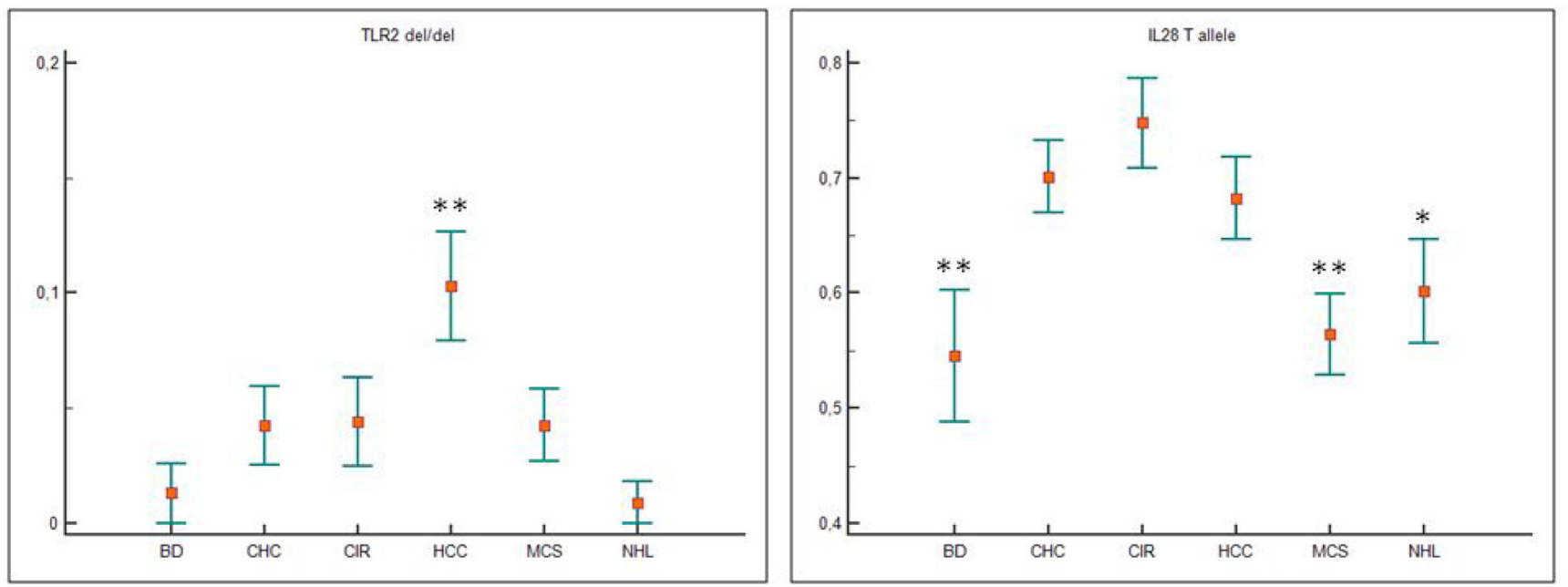

Figure 2: One-way Anova test for TLR2 and IL28B variant alleles and for TLR2 and IL28B genotypes. Data were represented as mean with Standard Error of measurement $( \pm$ SEM). Only statistically significant comparisons were illustrated. The del/del TLR2 genotype was significantly higher in patients with HCV-related hepatocellular carcinoma (HCC) compared to all the other groups $(p=0.004)(* *)$. Patients with HCV-related liver damage showed a higher IL28B T allele mean value than blood donors (BD) $(p=0.001$, $\mathrm{CHC}$ reference group) and patients with lymphoproliferative diseases (MSC and NHL, $p=0.012$, CHC reference group). 
Table 1: Main clinical and laboratory findings of HCV chronically infected patients according to liver-related damage and extrahepatic conditions.

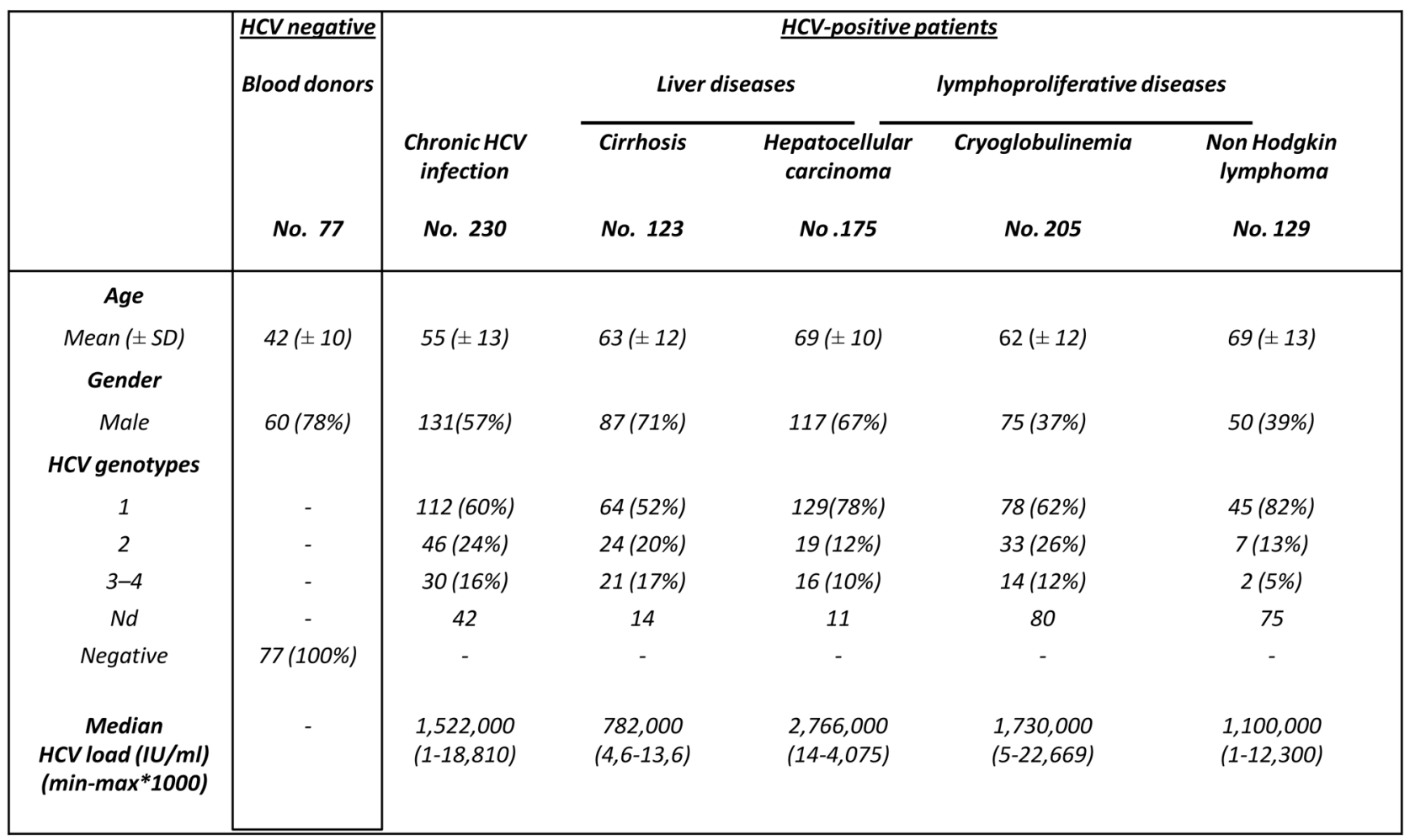

Nd: HCV genotype not determined

carrying TLR2 del/del genotype showed an increased risk for HCC compared with all other groups of patients and BDs by using pair wise comparison test (one-way analysis of variance HCC $v s$ NHL $p=0.004$; Figure 2). In particular, a positive trend between TLR2 del/ del genotype and an increasing risk for $\mathrm{HCC}$ (i.e CHC: $4.3 \%$; CIR: $4.9 \%$; HCC: $10.3 \%$ ) was found; by contrast, the TLR2 del/del prevalence in NHL patients $(0.9 \%)$ was similar to that found in BDs (1.3\%). Thus, findings indicated that TLR2 del/del genotype condition correlate with primary liver cancer rather than $\mathrm{HCV}$-positive malignant lymphoproliferation. No additional significant differences was observed for TLR2 ins/del genotype or allele frequencies.

\section{Genotype frequencies of rs12979860 IL28B polymorphism in chronic $\mathrm{HCV}$ infection, $\mathrm{HCV}$ - related liver and lymphoproliferative diseases}

The results of IL28B genotyping in patients with HCV-related diseases and BDs were shown in Figure 1. Distribution of rs 12979860 genotype frequencies found in our series was similar to those reported in the literature $[17,21,22]$. Results of previous studies where IL28B C/C genotype enhanced the spontaneous resolution of $\mathrm{HCV}$ infection indirectly support a possible role for the IL28B $\mathrm{C}$ allele in the control of $\mathrm{HCV}$ infection. In keeping with these observations, we found a negative trend for $\mathrm{CC}$ genotype frequencies, balanced by an increased trend in TT genotype, in $\mathrm{HCV}$-positive patients compared with BDs (IL28B C/C dominant polymorphism vs IL28B C/ $\mathrm{T}+$ IL28B T/T: OR $0.46 p=0.025$, Table 2). One-way test confirmed the significant positive trend for $\mathrm{T}$ allele in patients with chronic HCV-infection, which was more evident in patients with liver damage instead of a lymphoproliferative disorder (Figure 2). Thus, the analysis indicated a $\mathrm{T}$ allele gradient able to discriminate a chronic status more prone to evolve into liver injury from a condition more likely developing a lymphoproliferative dysfunction ( $p=0.001$, Figure 2). The frequency of IL28B $\mathrm{T}$ allele in $\mathrm{CHC}$, CIR , HCC was $43.7 \%$, in MCS, NHL was $35.1 \%$ in BDs was $27.2 \%$.

\section{TLR2-IL28B haplotypes in chronic $\mathrm{HCV}$ infection, HCV-related liver and lymphoproliferative diseases}

No linkage disequilibrium between TLR2 and IL28B polymorphisms was found as the test for correlation resulted not significant (862 data pairs tested; coefficient 
Table 2: Genotype associations with HCV infection

\begin{tabular}{|c|c|c|c|c|c|c|c|c|}
\hline \multirow[b]{2}{*}{\begin{tabular}{|l} 
Gene \\
polymorphism
\end{tabular}} & \multicolumn{2}{|c|}{ Dominant } & \multicolumn{2}{|c|}{ Recessive } & \multicolumn{2}{|c|}{ Additive 1} & \multicolumn{2}{|c|}{ Additive 2} \\
\hline & $P$-value & OR $(95 \%$ CI $)$ & $P$-value & OR (95\% CI) & $P$-value & $\begin{array}{ll}\text { OR } & (95 \% \\
\text { CI }) & \\
\end{array}$ & $P$-value & OR $(95 \%$ CI $)$ \\
\hline $\begin{array}{l}\text { TLR2 } \\
(\text { ins } \rightarrow \text { del })\end{array}$ & 0.521 & $\begin{array}{l}1.20 \\
2.06)\end{array}$ & 0.168 & $4.09(0.47-1.41)$ & 0.325 & $\begin{array}{l}0.76 \\
1.32)\end{array}$ & 0.167 & $4.118(0.55-30.61)$ \\
\hline $\begin{array}{l}\text { IL 28B } \\
\text { rs12979860 } \\
(\mathrm{C} \rightarrow \mathrm{T})\end{array}$ & 0.025 & $\begin{array}{l}0.46 \quad(0.28- \\
0.76)\end{array}$ & 0.260 & $1.99(0.60-6.58)$ & 0.082 & $\begin{array}{l}1.84 \\
3.66)\end{array}$ & 0.075 & $3.05(0.89-10.41)$ \\
\hline
\end{tabular}

HCV-positive patients $(n=862)$ were compared with respect to the reference category of blood donors $(n=77)$. OR, odds ratio; CI, confidential interval. WT: wild type is the most frequent polymorphism found in the general population. For the TLR2 SNP indicated like ins and del variant; a single band at $286 \mathrm{bp}$ was judged as WT, while heterozygous type revealed two bands of $286 \mathrm{bp}$ and $264 \mathrm{bp}$ (del variant). Genotypes of each polymorphism were assessed according to dominant (1 wild-type homozygote; 0 heterozygote and variant homozygote), recessive ( 0 wild-type homozygote and heterozygote; 1 variant homozygote) and additive genetic models. Additive models comprised additive 1 ( 1 heterozygotes versus 0 wildtype homozygotes) and additive 2 (1 variant homozygotes versus 0 wild-type homozygotes) models. Dominant indicated homzygous WT alleles, which was for the TLR2 the ins/ins genotype and for the IL28B the C/C genotype.

Table 3: Frequencies of TLR2 /IL-28B haplotypes based on HCV-related diseases and blood donors (BD).

\begin{tabular}{|c|c|c|c|c|c|c|c|}
\hline \multirow[b]{2}{*}{ TLR2 } & \multirow[b]{2}{*}{ IL28B } & \multicolumn{6}{|c|}{ frequency } \\
\hline & & $\begin{array}{c}\mathrm{BD} \\
\mathrm{N}=77\end{array}$ & $\begin{array}{c}\mathrm{CHC} \\
\mathrm{N}=230\end{array}$ & $\begin{array}{c}\mathrm{CIR} \\
\mathrm{N}=123\end{array}$ & $\begin{array}{c}\mathrm{HCC} \\
\mathrm{N}=175\end{array}$ & $\begin{array}{c}\text { MCS } \\
N=205\end{array}$ & $\begin{array}{c}\mathrm{NHL} \\
\mathrm{N}=129\end{array}$ \\
\hline Ins/ins & $\mathrm{CC}$ & 0.32 & 0.19 & 0.18 & 0.20 & 0.29 & 0.30 \\
\hline Ins/del +Del/del & $\mathrm{CC}$ & 0.13 & 0.11 & 0.06 & 0.12 & 0.14 & 0.11 \\
\hline Ins/ins & CT & 0.35 & 0.41 & 0.37 & 0.40 & 0.30 & 0.36 \\
\hline Ins/del+Del/del & CT & 0.12 & 0.17 & 0.14 & 0.12 & 0.16 & 0.11 \\
\hline Ins/ins & TT & 0.08 & 0.08 & 0.13 & 0.11 & 0.10 & 0.11 \\
\hline Ins/del+Del/del & TT & ---- & 0.04 & 0.05 & 0.05 & 0.03 & 0.01 \\
\hline
\end{tabular}

Usually, TLR2 SNP has indicated like -196 to -174 del. A single band at 286 bp was judged as wild type, and a single 264 bp band was judged as homozygous type, while heterozygous type revealed two bands of $286 \mathrm{bp}$ and $264 \mathrm{bp}$. 
Table 4: TLR2-IL28B haplotype association with blood donors and HCV-positive patients affected by liver (cirrhosis and hepatocellular carcinoma) or lymphoproliferative diseases (type II cryoglobulinemia and non-Hodgkin's lymphoma) compared with respect to chronic HCV infection (CHC).

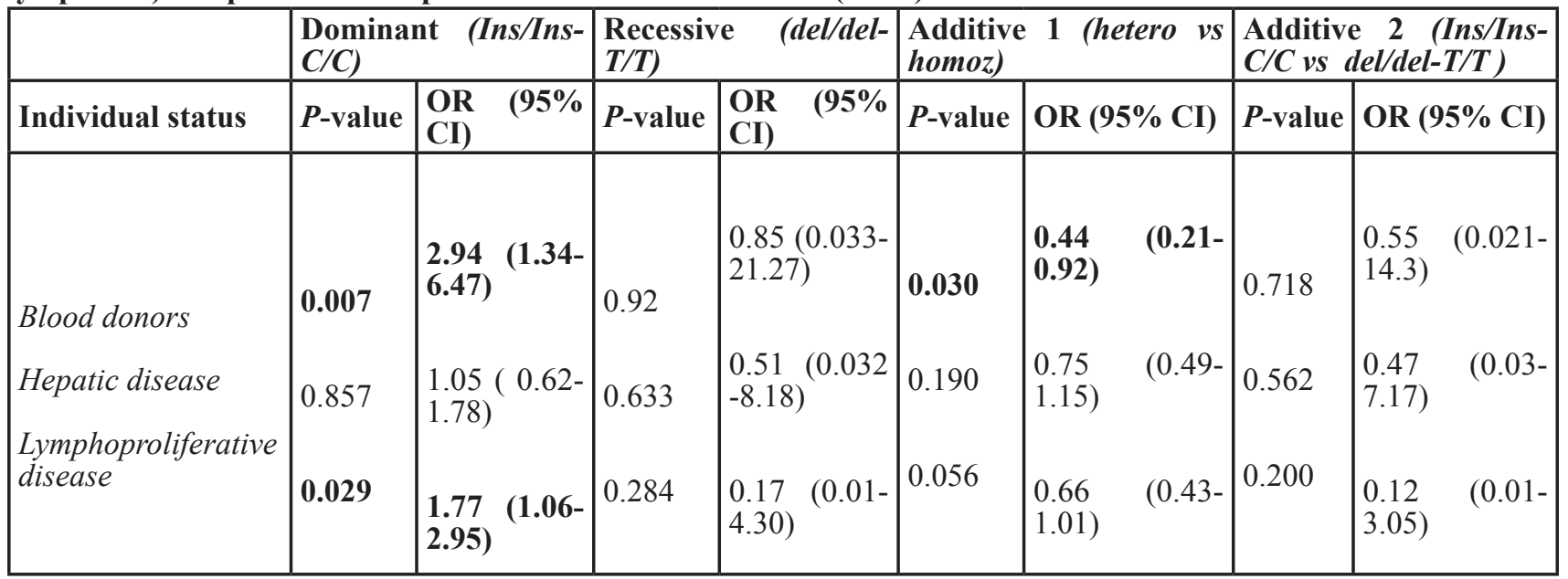

Reference category: $\mathrm{CHC}$, chronic HCV-positive patients Abbreviations: OR, odds ratio; CI, confidential interval.

of correlation 0.03 ). The TLR2-IL28B polymorphisms formed several haplotypes, whose frequency was reported on Table 3. The distribution analysis of haplotypes confirmed that specific haplotypes discriminated between HCV-positive patients more likely evolving towards liver damage and those instead evolving towards a lymphoproliferative disorder. Indeed, a significant lack of the TLR2-ins/ins IL28B-C/C haplotype was not only associated with a chronic HCV status $(p=0.007$, OR 2.94, Table 4) but closely correlated with a liver damage, rather than a lymphoproliferative-disease progression ( $p=\mathrm{ns}$, OR $1.05 ; p=0.029$, OR 1.77, respectively, Table 4).

\section{Relationship between HCV viral load and TLR2- IL28B haplotype}

$\mathrm{HCV}$ viral load was assessed in serum samples for 197 patients at diagnosis. A higher $\mathrm{HCV}$ viral load was mainly associated with the presence of IL28B C/C rather than that of IL28B T/T genotype (IL28B additive $2, p=0.005$, HR 1.68, 95\% CI 1.02-2.75, Table 5) and TLR2 ins/del genotype than homozygous (TLR2 additive $1, p=0.026$, HR 1.30, 95\%CI 0.96-1.73). Multivariate regression analysis indicated that IL $28 \mathrm{~B} \mathrm{~T} / \mathrm{T}$ recessive genotype was independent of HCV genotype, age, patient gender and TLR2 variables and it was associated with a lower HCV viral load ( $p=0.044$, exp $1.5295 \%$ CI 1.012.27).

\section{Relationship between liver disease progression and TLR2- IL28B haplotype}

Given the potential role of host immunity in the control of HCV-infected tumor cells and the potential of age-related influences on tumor progression, we also looked for a liver disease age-related trend and TLR2IL28B haplotype. Continuous age variable was analyzed between liver and lymphoproliferative groups with respect to the dominant wild-type TLR2- IL28B haplotype, and a significant association was found with BDs and patients with a lymphoproliferative disease. A significant difference was found in the mean age between patients having a dominant haplotype and a liver disease compared to those having a different haplotype (CIR patients: 68.9 vs 62.0 mean age, $p=0.038$; HCC: 72.4 vs 67.7 mean age, $p=0.02$; Figure 3 ).

\section{DISCUSSION}

Immunogenetic profile may play an important role in determining the progression of chronic $\mathrm{HCV}$ infections to different diseases [1-3, 5, 27]. We confirmed the role of rs12979860 IL28B-C allele-carrier as a protective factor for $\mathrm{CHC}[2,17,21-26]$. In addition, we highlighted that the IL28B C/C genotype correlates with lymphoproliferative disease when associated with a TLR2-ins allele in homozygosity (Table 4). On the contrary, homozygous TLR2-del allele (TLR2-del/ del) exhibits a significantly higher threshold for HCC development (Figure 2). Overall, the present results were consistent with an interlocked role between TLR2 and IL28B (IFN- $\lambda 3$ ) gene variants in directing HCV-related 
Table 5: TLR2 and $I L 28 B$ genotype and $T L R 2-I L 28 B$ haplotype association with HCV viral load

\begin{tabular}{|c|c|c|c|c|c|c|c|c|}
\hline \multicolumn{9}{|c|}{ UNIVARIATE ANALYSIS } \\
\hline & \multicolumn{2}{|c|}{ Dominant } & \multicolumn{2}{|c|}{ Recessive } & \multicolumn{2}{|c|}{ Additive 1} & \multicolumn{2}{|c|}{ Additive 2} \\
\hline & P-value & $\mathrm{HR}(95 \% \mathrm{Cl})$ & P-value & HR (95\% Cl) & P-value & $\mathrm{HR}(95 \% \mathrm{Cl})$ & P-value & $\mathrm{HR}(95 \% \mathrm{Cl})$ \\
\hline \multicolumn{9}{|l|}{$T L R 2$} \\
\hline$($ ins $\rightarrow$ del) & 0.564 & $1.07(0.80-1.44)$ & 0.968 & $0.95(0.55-1.77)$ & 0.026 & $1.30(0.96-1.73)$ & 0.920 & $1.02(0.57-1.84)$ \\
\hline \multicolumn{9}{|l|}{ IL28B } \\
\hline$r s 12979860(C \rightarrow T)$ & 0.041 & $1.27(0.95-1.68)$ & 0.022 & $0.68(0.43-1.07)$ & 0.691 & $0.96(0.72-1.26)$ & 0.005 & $1.68(1.02-2.75)$ \\
\hline $\begin{array}{l}\text { TLR2-IL28B } \\
\text { haplotype }\end{array}$ & 0.054 & $1.38(1.011-1.87)$ & 0.823 & $0.80(0.09-7.18)$ & 0.44 & $1.13(0.76-1.68)$ & 0.790 & $1.29(0.14-12.20)$ \\
\hline
\end{tabular}

MULTIVARIATE ANALYSIS

IL28B

rs12979860 $(C \rightarrow T) \quad 0.044, \exp 1.5295 \%$ Cl 1.01-2.27

\begin{abstract}
Abbreviations: HR. hazard ratio; CI. confidential interval. Hazard ratio; CI. confidential interval. Hazard ratio; CI. confidential interval. WT: wild type is the most frequent polymorphism found in the general population. For the TLR2 SNP indicated like ins and del variant; a single band at $286 \mathrm{bp}$ was judged as WT, while heterozygous type revealed two bands of $286 \mathrm{bp}$ and $264 \mathrm{bp}$ (del variant). Genotypes of each polymorphism were assessed according to dominant (1 wild-type homozygote; 0 heterozygote and variant homozygote), recessive ( 0 wild-type homozygote and heterozygote; 1 variant homozygote) and additive genetic models. Additive models comprised additive 1 ( 1 heterozygotes versus 0 wild-type homozygotes) and additive 2 (1 variant homozygotes versus 0 wild-type homozygotes) models. Dominant indicated homozygous WT alleles, which was for the TLR2 the ins/ins genotype and for the IL28B the C/C genotype. Multivariate stepwise tested for age, sex, HCV genotype, TLR2 and IL28B variables.
\end{abstract}

diseases progression. Indeed, it has been shown that TLR2 was able to activate transcription factors that drive the expression of antiviral genes and different cytokines, such as interferons $[15,16]$. Several studies have indicated a relation among rs12979860 IL28B gene, spontaneous clearance of $\mathrm{HCV}$ and therapeutic outcomes of genotype $1 \mathrm{HCV}$-positive patients treated with IFN-based therapies $[2,21-26]$. In 2013 a new interferon, the IFN- $\lambda 4$, was identified. The rs368234815 polymorphism originating the IFN $-\lambda 4$ by creation of a new open reading frame $[19$, 28] was found in strong linkage disequilibrium with the rs12979860 IL28B so much it has been described as the functional variant of the rs 12979860 IL28B $[19,29]$. Thus, spontaneous and treatment-induced clearance of $\mathrm{HCV}$ resulted equally dependent on rs12979860 or rs368234815 polymorphisms and combined assessment of these gene polymorphisms did not increase the predictive value of IL28B polymorphisms in HCV-positive patients [19, 29]. More recently, it was found that $\mathrm{Y} 93 \mathrm{H}$, a variant present in the NS5A region of $\mathrm{HCV}$, was significantly associated with the beneficial rs12979860 polymorphism confirming the functional role of IFN- $\lambda 4$ SNP in HCV-infection [30]. The haplotype data presented herein (Table 4) provided evidence supporting a role for IL28B in relation with TLR2 polymorphism to predict progression to different HCV-related diseases. Recent functional studies have demonstrated that IL28B T/T genotype was associated with a higher production of IFN- $\lambda 3$ and higher ISGs gene expression in $\mathrm{HCV}$-infected liver tissue, and that this higher baseline level of ISGs expression may contribute to an interferon-refractory state in the liver [31]. Thus, it has been hypothesized that the high baseline ISG levels found in IL28B T/T carriers can lead to a poor response to INF-based therapy due to an exhaustion of the interferonresponse pathway [32]. In keeping with this model, a satisfactory treatment response could be associated with a IL28 C/C genotype, a lower levels of ISGs expression and thus a higher levels of circulating HCV RNA [33]. Our findings about higher viral load in patients having IL28B C/C genotype may support this hypothesis. A higher viral load was associated with HCV genotype 1, but difference among genotypes did not reach a statistical significance in our series. The observed broader frequency of IL28-T allele in patients with hepatic rather than lymphoproliferative disorders can be explained by the fact that the IL28-R/IL-10R receptor complex was expressed only in restricted cell types, like hepatocytes, epithelial cells and plasmacytoid dendritic cells [34]. Considering that $\mathrm{HCV}$ was primarily hepatotropic, it is reasonable to assume that IL28B-T allele could likely contribute to an IFN-refractory state mostly in the liver. In this regard, it has been observed that the expression levels of ISGs were differentially regulated in the liver and peripheral blood $[35,36]$. In addition, higher level of HCV infection in hepatocytes induced higher level of endoplasmatic reticulum stress and caused HCC carcinogenesis [37]. In this scenario, TLR2-del variant, which was related to a diminished expression of TLR2 level, and secretion 
of immunosuppressive cytokines, increased the hepatic inflammatory microenvironment and the risk of HCC development [8, 13, 38]. Consistently, TLR2 knockdown (TLR2 $\%$ ) mice showed enhanced inflammation, hepatic lesions and HCC progression after carcinogenic diethylnitrosamine exposure [9, 39]. Moreover, the TLR2 $\mathrm{del} /$ del condition resulted more frequently detected in our $\mathrm{HCC}$ patients than in other HCV-related diseases (Figure 2 ). Data were in agreement with those observed in the HCV German population with an increased risk of HCC associated with the TLR2-del variant [13]. On the other hand, our multivariate analysis showed that IL28B C/C genotype was associated with a higher viral load (Table 5) and that the dominant wild-type haplotype (TLR2 ins/insIL28B C/C) correlated with lymphoproliferative diseases but also with BDs (Table 4). Likewise, previous studies have shown that $\mathrm{HCV}$-core protein triggering TLR2 leaded to an increased in B-cell proliferation in vitro [18]. Thus, considering that $\mathrm{HCV}$ is also a lymphotropic virus, our haplotype analysis pointed out that in the presence of a HCV chronic persistence, the TLR2 ins/ins-IL28B$\mathrm{C} / \mathrm{C}$ arrangement could increase the susceptibility to lymphoproliferative complications, including mixed cryoglobulinemia and B-cell NHL $(p=0.029$, OR 1.77 , Table 4). In addition, the TLR2 ins/ins-IL28B-C/C haplotype not only showed a potential protective effect against $\mathrm{HCV}$ infection but also an association with older patients having a liver diseases (CIR and HCC, Figure 3), thus, suggesting that the protective effect associated with this haplotype decreased with age.

In conclusion, our study emphasizes that both TLR2 and IL28B polymorphisms may have a role in directing $\mathrm{HCV}$-progression towards hepatic or lymphoproliferative diseases. Thus, the analysis of our HCV-positive population stratified by the two immunological variables indicated a potential protective effect of the IL28B-C

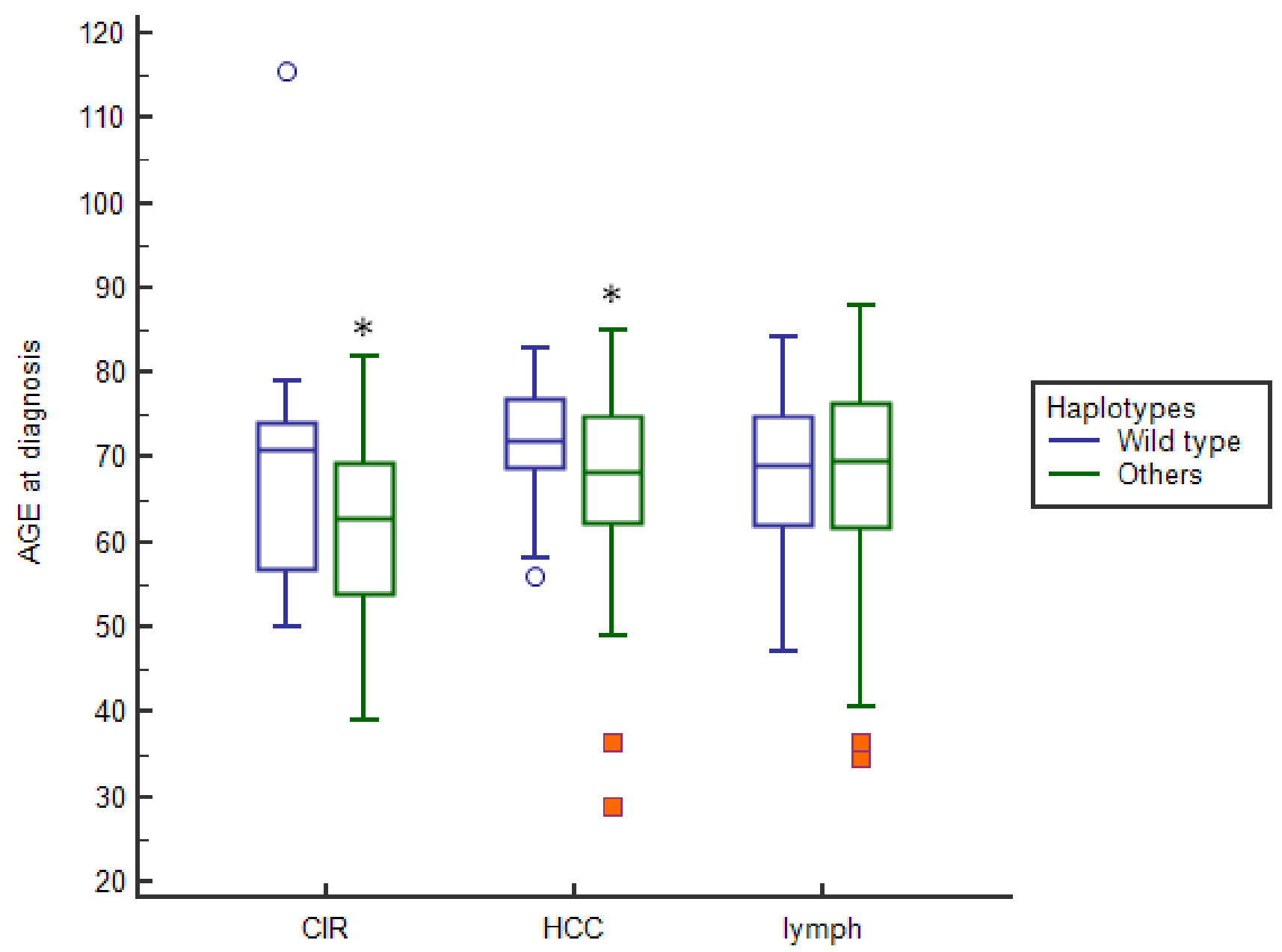

Figure 3: Boxplot describing the relationship of TLR2-IL28B haplotype with the patient disease stratified by the median age at diagnosis. Boxes range from the 25 th to the 75 th percentile with a horizontal black line at the median and vertical lines extending to the 10th and 90th percentiles. The wild type TLR2-IL28B haplotype showed an association with the older patients having a liver disease (patients with HCV-related cirrhosis $(\mathrm{CIR})(*)(p=0.038)$ and patients with HCV-related hepatocellular carcinoma $(\mathrm{HCC})(*)(p$ $=0.02$ ). We found no difference in the median age at diagnosis in patients with lymphoproliferative diseases. 
allele in homozygosity (IL28B-C/C) towards chronic infection and liver diseases, and that the simultaneous presence of at least one TLR2-del allele abolished this effect. In accordance with this result, the TLR2-del/ del state appeared closely linked with HCC condition. Conversely, the dominant wild-type haplotype (TLR2 ins/ins-IL28B C/C) associated with a better spontaneous resolution of the infection was also found more frequently in both BDs as well as in HCV-related lymphoproliferative disorders compared to $\mathrm{CHC}$, suggesting that, in patients with a lymphoproliferative disease, additional factors may be involved that obstacle the elimination of the virus. Therefore, our findings shed new light on the mechanisms underlying the persistence of $\mathrm{HCV}$ infection and $\mathrm{HCV}$ related disease progression. A deeper understanding of these processes may lead to development of strategies based on the combination of conventional therapies with immune-mediated strategies for the treatment of $\mathrm{HCV}$ related diseases.

\section{MATERIALS AND METHODS}

\section{Study samples}

We considered 862 patients with chronic HCVinfection and 77 healthy blood donors. The ethnic background of patients was caucasic, without HBV or HIV infection. Among HCV-positive patients, 230 had a chronic HCV infection (CHC $n=230$ ), 123 patients had cirrhosis (CIR $n=123$ ), 175 patients had hepatocellular carcinoma (HCC), and 334 patients had a lymphoproliferative disease including: 205 a cryoglobulinemic syndrome (MCS) defined according to previously described criteria [3] and 129 an overt B-cell non-Hodgkin's lymphoma (NHL). Demographic and clinical characteristics of each groups were reported on Table 1. Patients had been recruited from: the MASVE Center, University of Florence, Azienda Ospedaliera Santa Maria degli Angeli, Pordenone, National Cancer Institute "Fondazione Pascale", Naples, Departement of Biomedical Sciences and Human Oncology, University of Bari Medical School, Policlinico Universitario di Udine and Centro di Riferimento oncologico di Aviano, Italy. The diagnosis of chronic HCV infection was based on anti-HCV, elevated ALT serum levels and HCV RNA positivity of at least 6 months duration. An immunoassay test (III-generation EIA) against $\mathrm{HCV}$-core and $\mathrm{HCV}$ non structural antigens were used. HCV genotype was determined by a commercial, certified, diagnostic test (Versant HCV Genotype 2.0, Siemens Healthcare Diagnostics, Deerfield, IL). Quantitative determination of HCV loads (RNA UI/mL) was done by branched DNA technology (Chiron, Emeryville, CA). The diagnosis of HCC was based on the standard criteria listed in the
European Association for the Study of the Liver (EASL) that incorporate both invasive and noninvasive measures. Noninvasive criteria include two imaging techniques, both demonstrating a focal lesion $>2 \mathrm{~cm}$ in diameter with features of arterial hypervascularization. Detection and immunochemical characterization of cryoglobulins were performed according to consensus protocol proposed by A.L.CRI (Associazione Italiana per la Lotta alle Crioglobulinemie). NHL in the course of HCV infection has been histopathologically confirmed based on WHO classification [3]. The study was conformed to the ethical guidelines of the Helsinki Declaration and all subjects provided informed consent. Study was approved by independent local and independent ethics committees since this was a multicenter study.

\section{Genetic polymorphisms of TLR2 and IL28B}

Genomic DNA was extracted from whole blood using the EZ1 Qiagen blood kit and protocols recommended by the manufacturer (Qiagen Inc., Valencia, CA). Determination of TLR2 -196 to -174 ins/ del polymorphism was performed by Polymerase Chain Reaction (PCR) using the 5'-ctcggaggcagcgagaaa-3' and 5 '-ctgggccgtgcaaagaag-3' primers (10 pmol) in a reaction volume of $25 \mu \mathrm{l}$ including $200 \mathrm{ng}$ dNTPs and $0.5 \mathrm{U}$ of GoTaq DNA Polymerase (Promega Corporation, Madison, WI). Cycling conditions were: initial denaturation at 95 ${ }^{\circ} \mathrm{C}$ for $5 \mathrm{~min}$, followed by 35 cycles at $95^{\circ} \mathrm{C}$ for $30 \mathrm{sec}$, at $60^{\circ} \mathrm{C}$ for $40 \mathrm{sec}$ and at $72{ }^{\circ} \mathrm{C}$ for $40 \mathrm{sec}$ and then 72 ${ }^{\circ} \mathrm{C}$ for $7 \mathrm{~min}$. Fragments of different length (264 bp and $286 \mathrm{bp}$ ), depending on the presence or absence of the deletion mutation were visualized by electrophoresis on a $3.5 \%$ agarose gel staining with ethidium bromide. IL28B genotyping was performed using a specific custom TaqMan SNP-genotyping Assay (SNP rs12979860; Applied Biosystem, Foster City, CA, USA) based on allele-specific dual-labelled probes on a 7900HT Fast Real-Time PCR system (Applied Biosystem, Foster City, CA, USA). Amplicon sequencing was used to validate the genotyping techniques.

\section{Statistical analysis}

Specific tests including Fisher's exact test and one or two-way analysis of variance were used to compare the patient groups regarding allele and genotype frequencies of TLR2 and IL28B polymorphisms, by direct counting of the positive individuals for a specific allele/genotype polymorphism. Multivariate logistic regression analysis was performed with diagnosis as a dependent variable and independent variables, including age, gender (0 female; 1 male), and each genotype were also considered. $\mathrm{P}$-value, odds ratio and 95\% confidence interval were calculated. Genotypes of each polymorphism were 
assessed according to dominant (0 wild-type homozygote; 1 heterozygote and variant homozygote), recessive (0 wild-type homozygote and heterozygote; 1 variant homozygote) and additive genetic models. Additive models comprised additive 1 (heterozygotes versus wildtype homozygotes) and additive 2 (variant homozygotes versus wild-type homozygotes) models, which were analyzed simultaneously with a single statistical model. Statistical analyses were performed using GraphPad Prism v6. $P$ value $<0.05$ was considered significant.

\section{ACKNOWLEDGMENTS}

This work was supported by The Associazione Italiana Ricerca Cancro (AIRC), Investigator Grant IG14973.

\section{CONFLICTS OF INTEREST}

The authors declare no competing financial interests.

\section{REFERENCES}

1. Rehermann B, Bertoletti A. Immunological aspects of antiviral therapy of chronic hepatitis B virus and hepatitis C virus infections. Hepatology. 2015; 61: 712-721.

2. Conteduca V, Sansonno D, Russi S, Pavone F, Dammacco F. Therapy of chronic hepatitis $\mathrm{C}$ virus infection in the era of direct-acting and host-targeting antiviral agents. Journal of Infection. 2014; 68: 1-20.

3. De Re V, Caggiari L, De Zorzi M, Repetto O, Zignego A, Izzo F, Tornesello ML, Buonaguro FM, Mangia A, Sansonno D, Racanelli V, De Vita S, Pioltelli P, et al.. Genetic Diversity of the KIR/HLA System and Susceptibility to Hepatitis C Virus-Related Diseases. PLoS ONE. 2015; 10: e0117420.

4. Guo J, Friedman S. Toll-like receptor 4 signaling in liver injury and hepatic fibrogenesis. Fibrogenesis \& Tissue Repair. 2010; 3: 21.

5. Horner S. Activation and Evasion of Antiviral Innate Immunity by Hepatitis C Virus. Journal of Molecular Biology. 2014; 426 : 1198-1209.

6. Kesar V, Odin J. Toll-like receptors and liver disease. Liver International. 2013; 34: 184-196.

7. Tarantino G, Di Cristina A, Pipitone R, Almasio PL, Di Vita G, Craxi A, Grimaudo S. In vivo liver expression of TLR2, TLR3 and TLR7 in chronic hepatitis C. J Biol Regul Homeost Agents. 2013; 27: 233-239.

8. Li S, Sun R, Chen Y, Wei H, Tian Z. TLR2 Limits Development of Hepatocellular Carcinoma by Reducing IL18-Mediated Immunosuppression. Cancer Research. 2015; 75:986-995.

9. Lin H, Yan J, Wang Z, Hua F, Yu J, Sun W, Li K, Liu H, Yang H, Lv Q, Xue J, Hu ZW. Loss of immunity-supported senescence enhances susceptibility to hepatocellular carcinogenesis and progression in Toll-like receptor 2-deficient mice. Hepatology. 2013; 57: 171-182.

10. Ronit A, Salem M, Hartling HJ, Gaardbo JC, Ullum H, Gerstoft J, Nielsen SD. Dysregulation of toll-like receptor (TLR) 2 expression on monocytes and upregulation of the frequency of $\mathrm{T}$ cells expressing TLR 2 in patients with chronic hepatitis C virus infection. APMIS. 2013; 121: 437 446.

11. Dolganiuc A, Oak S, Kodys K, Golenbock DT, Finberg RW, Kurt-Jones E, Szabo G. Hepatitis c core and nonstructural 3 proteins trigger toll-like receptor 2-mediated pathways and inflammatory activation. Gastroenterology. 2004; 127: 1513-1524.

12. Dolganiuc A, Chang S, Kodys K, Mandrekar P, Bakis G, Cormier M, Szabo G. Hepatitis c virus (hev) core proteininduced, monocyte-mediated mechanisms of reduced ifnalpha and plasmacytoid dendritic cell loss in chronic hev infection. J Immunol. 2006; 177: 6758-6768.

13. Nischalke H, Coenen M, Berger C, Aldenhoff K, Müller T, Berg T, Krämer B, Körner C, Odenthal M, Schulze F, Grünhage F, Nattermann J, Sauerbruch T et al. The tolllike receptor 2 (TLR2) -196 to -174 del/ins polymorphism affects viral loads and susceptibility to hepatocellular carcinoma in chronic hepatitis C. International Journal of Cancer. 2011; 130: 1470-1475.

14. Tahara T, Arisawa T, Wang F, Shibata T, Nakamura M, Sakata M Hirata I, Nakano H. Toll-like receptor 2-196 to $174 \mathrm{del}$ polymorphism influences the susceptibility of Japanese people to gastric cancer. Cancer Science. 2007; 98: 1790-1794.

15. Ank N, Iversen MB, Bartholdy C, Staeheli P, Hartmann R, Jensen UB, Dagnaes-Hansen F, Thomsen AR, Chen Z, Haugen H, Klucher K, Paludan SR. An important role for type III interferon (IFN-lambda/IL-28) in TLR-induced antiviral activity. J Immunol. 2008; 180: 2474-85.

16. Coccia EM, Severa M, Giacomini E, Monneron D, Remoli ME, Julkunen I, Cella M, Lande R, Uzé G. Viral infection and Toll-like receptor agonists induce a differential expression of type I and lambda interferons in human plasmacytoid and monocyte-derived dendritic cells. Eur J Immunol. 2004; 34: 796-805.

17. De Re V, Gragnani L, Fognani E, Piluso A, Izzo F, Mangia A, Crovatto M, Gava G, Casarin P, Sansonno D, Racanelli V, De Vita S, Pioltelli P et al. Impact of Immunogenetic IL28B Polymorphism on Natural Outcome of HCV Infection. BioMed Research International. 2014; 1-8.

18. Feldmann G, Nischalke HD, Nattermann J, Banas B, Berg T, Teschendorf C, Schmiegel W, Dührsen U, Halangk J, Iwan A, Sauerbruch T, Caselmann WH, Spengler U. Induction of Interleukin-6 by Hepatitis C Virus Core Protein in Hepatitis C-Associated Mixed Cryoglobulinemia and B-Cell Non-Hodgkin's Lymphoma. Clinical Cancer Research. 2006; 12: 4491-4498. 
19. Prokunina-Olsson L, Muchmore B, Tang W, Pfeiffer R, Park H, Dickensheets H, Hergott D, Porter-Gill P, Mumy A, Kohaar I, Chen S, Brand N, Tarway M et al. A variant upstream of IFNL3 (IL28B) creating a new interferon gene IFNL4 is associated with impaired clearance of hepatitis C virus. Nature Genetics. 2013; 45: 164-171.

20. Odendall C, Kagan J. The unique regulation and functions of type III interferons in antiviral immunity. Current Opinion in Virology. 2015; 12: 47-52.

21. Falleti E, Bitetto D, Fabris C, Cussigh A, Fornasiere E, Cmet S, Fumolo E, Bignulin S, Fontanini E, Cerutti A, Minisini R, Pirisi M, Toniutto P. Role of Interleukin 28B rs12979860 C/T Polymorphism on the Histological Outcome of Chronic Hepatitis C: Relationship with Gender and Viral Genotype. Journal of Clinical Immunology. 2011; 31: 891-899.

22. Ge D, Fellay J, Thompson A, Simon J, Shianna K, Urban TJ, Heinzen EL, Qiu P, Bertelsen AH, Muir AJ, Sulkowski M, McHutchison JG, Goldstein DB. Genetic variation in IL28B predicts hepatitis C treatment-induced viral clearance. Nature. 2009; 461: 399-401.

23. Mancuso ME, Linari S, Aghemo A, Bartolozzi D, Santagostino E, Rumi MG, Fognani E, Fasulo MR, Gragnani L, Bruno R, Morfini M, Zignego AL, Colombo M. Interferon lambda 3 rs 12979860 polymorphism in patients with haemophilia and HCV infection: a predictor of spontaneous viral clearance and sustained virological response. Thromb Haemost. 2014; 111: 1067-1076.

24. Mangia A, Mottola L, Santoro R. Interleukin 28B polymorphisms as predictor of response in hepatitis $\mathrm{C}$ virus genotype 2 and 3 infected patients. World Journal of Gastroenterology. 2013; 19: 8924-8928.

25. Sarrazin C, Susser S, Doehring A, Lange CM, Müller T, Schlecker C, Herrmann E, Lötsch J, Berg T. Importance of IL28B gene polymorphisms in hepatitis $\mathrm{C}$ virus genotype 2 and 3 infected patients. Journal of Hepatology. 2011; 54: 415-421.

26. Susser S, Herrmann E, Lange C, Hamdi N, Müller T, Berg T, Perner D, Zeuzem S, Sarrazin C. Predictive Value of Interferon-Lambda Gene Polymorphisms for Treatment Response in Chronic Hepatitis C. PLoS ONE. 2014; 9: e112592.

27. Dustin L. Innate and Adaptive Immune Responses in Chronic HCV infection. Current Drug Targets. 2015; 16:11.

28. Bibert S, Roger T, Calandra T, Bochud M, Cerny A, Semmo N, Duong FH, GerlachT, Malinverni R, Moradpour D, Negro F, Müllhaupt B, Bochud PY. Swiss Hepatitis C Cohort Study. IL28B expression depends on a novel TT/-G polymorphism which improves HCV clearance prediction. J Exp Med. 2013; 210: 1109-1116.

29. Hamming OJ, Terczyńska-Dyla E, Vieyres G, Dijkman R, Jørgensen SE, Akhtar H,Siupka P, Pietschmann T, Thiel V, Hartmann R. Interferon lambda 4 signals via the IFNlambda receptor to regulate antiviral activity against $\mathrm{HCV}$ and coronaviruses. EMBO J. 2013; 32: 3055-3065.

30. Peiffer KH, Sommer L, Susser S, Vermehren J, Herrmann E, Döring M, Dietz J, Perner D, Berkowski C, Zeuzem S, Sarrazin C. Interferon lambda 4 genotypes and resistanceassociated variants in patients infected with hepatitis C virus genotypes 1 and 3. Hepatology. 2016; 63: 63-73:

31. Noureddin M, Rotman Y, Zhang F, Park H, Rehermann B, Thomas E, Liang TJ. Hepatic expression levels of interferons and interferon-stimulated genes in patients with chronic hepatitis $\mathrm{C}$ : A phenotype-genotype correlation study. Genes and Immunity. 2015; 16: 321-329.

32. Stättermayer A, Ferenci P. Effect of IL28B genotype on hepatitis B and $\mathrm{C}$ virus infection. Current Opinion in Virology. 2015; 14: 50-55.

33. Urban TJ, Thompson AJ, Bradrick SS, Fellay J, Schuppan D, Cronin KD, Hong L, McKenzie A, Patel K, Shianna KV, McHutchison JG, Goldstein DB, Afdhal N. IL28B genotype is associated with differential expression of intrahepatic interferon-stimulated genes in patients with chronic hepatitis C. Hepatology. 2010; 52: 1888-1896.

34. Sommereyns C, Paul S, Staeheli P, Michiels T. IFNLambda (IFN- $\lambda$ ) Is Expressed in a Tissue-Dependent Fashion and Primarily Acts on Epithelial Cells In Vivo. PLoS Pathogens. 2008; 4: e1000017.

35. Abe H, Hayes CN, Ochi H, Maekawa T, Tsuge M, Miki D, Mitsui F, Hiraga N, Imamura M, Takahashi S, Kubo M, Nakamura Y, Chayama K. IL28 variation affects expression of interferon stimulated genes and peg-interferon and ribavirin therapy. Journal of Hepatology. 2011; 54: 10941101.

36. O'Brien T, Prokunina-Olsson L, Donnelly R. IFN- $\lambda$ 4: The Paradoxical New Member of the Interferon Lambda Family. Journal of Interferon \& Cytokine Research. 2014; 34: 829838 .

37. Olivares S, Green R, Henkel A. Endoplasmic Reticulum Stress Activates the Hepatic Activator Protein 1 Complex via Mitogen Activated Protein Kinase-Dependent Signaling Pathways. PLoS ONE. 2014; 9: e103828.

38. Castaño-Rodríguez N, Kaakoush N, Pardo A, Goh K, Fock $\mathrm{K}$, Mitchell H. Genetic polymorphisms in the Toll-like receptor signalling pathway in Helicobacter pylori infection and related gastric cancer. Human Immunology. 2014; 75 : 808-815.

39. Lin H, Liu X, Yu J, Hua F, Hu Z. Antioxidant N-Acetylcysteine Attenuates Hepatocarcinogenesis by Inhibiting ROS/ER Stress in TLR2 Deficient Mouse. PLoS ONE. 2013; 8: e74130. 